\title{
CrystEngComm
}

PAPER

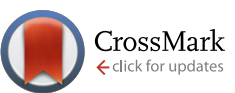

Cite this: CrystEngComm, 2014, 16, 11027

\section{Self-assembled hierarchical $\beta$-cobalt hydroxide nanostructures on conductive textiles by one-step electrochemical deposition $\dagger$}

\author{
Goli Nagaraju, Yeong Hwan Ko and Jae Su Yu*
}

\begin{abstract}
Three-dimensional (3D) hierarchical cabbage-like $\beta$-cobalt hydroxide $\left(\beta\right.$ - $\left.\mathrm{Co}(\mathrm{OH})_{2}\right)$ nanostructures were fabricated onto conducive textiles composed of copper-coated polyethylene terephthalate fibers by a simple one-step electrochemical deposition (ED) method. Under an external applied voltage of $-0.75 \mathrm{~V}$ for $4 \mathrm{~h}$, the hierarchical cabbage-like $\beta-\mathrm{Co}(\mathrm{OH})_{2}$ nanostructures were well decorated on the conductive textiles. During the ED process, they were self-assembled by the tangled layers of nanoplate (thickness of $\sim 45-55 \mathrm{~nm}$ ) building blocks and exhibited a cabbage-shaped architecture. The structure and morphology of the as-prepared hierarchical cabbage-like $\beta-\mathrm{Co}(\mathrm{OH})_{2}$ nanostructures were characterized. The growth mechanism of cabbage like $\beta-\mathrm{Co}(\mathrm{OH})_{2}$ nanostructures was also investigated by varying the growth time. Moreover, the feasibility test for supercapacitors by measuring the electrochemical properties of the as-prepared nanostructures was performed by cyclic voltammetry and galvanic charge-discharge measurements. The obtained results show that the cabbage-like $\beta-\mathrm{Co}(\mathrm{OH})_{2}$ nanostructures on the conductive textile substrate exhibited superior energy storage performance compared to the nanoplate morphology.
\end{abstract}

Received 16th August 2014, Accepted 20th October 2014

DOI: $10.1039 / c 4 c e 01696 c$

www.rsc.org/crystengcomm supercapacitors, lithium-ion batteries, catalysts for water splitting, sensors, etc. ${ }^{11-13}$ It is well known that $\mathrm{Co}(\mathrm{OH})_{2}$ has two polymorphs, $\alpha$ - and $\beta-\mathrm{Co}(\mathrm{OH})_{2}$. These structures provide a high redox activity in supercapacitors due to their layered structure with large interlayer spacing. Accordingly, many studies have been concentrated on controlling their size, morphology, and geometry to increase the potentiality of specific applications. ${ }^{14,15}$ Especially, three-dimensional (3D) hierarchical $\mathrm{Co}(\mathrm{OH})_{2}$ nanostructures such as urchin-shaped spheres and flower-like structures have exhibited excellent electrochemical properties because they provide high surface area, efficient charge transportation, and highly exposed electrochemically active sites for electrolyte diffusion. ${ }^{16,17}$ However, these 3D hierarchical $\mathrm{Co}(\mathrm{OH})_{2}$ architectures still require somewhat complicated fabrication processes. Typically, the 3D building blocks can be synthesized by a surfactant, template-assisted chemical synthesis method. ${ }^{18,19}$

In this work, we fabricated the 3D hierarchical cabbage-like $\beta-\mathrm{Co}(\mathrm{OH})_{2}$ nanostructures on conductive textile substrates by one-step electrochemical deposition (ED) which is a simple and facile way for preparing various metal oxide/hydroxide nanostructures. By controlling the growth time under an optimized external applied voltage, cabbage-like $\beta-\mathrm{Co}(\mathrm{OH})_{2}$ nanostructures were self-assembled by the nanoplates and multilayered nanoplate building blocks. Also, a feasibility test for supercapacitors was performed, together with physical and chemical property studies of these nanostructures.
Department of Electronics and Radio Engineering, Institute for Laser Engineering, Kyung Hee University, 1 Seocheon-dong, Giheung-gu, Yongin-si, Gyeonggi-do 446-701, Republic of Korea. E-mail: jsyu@khu.ac.kr; Fax: +82 31206 2820;

Tel: +82312013820

$\dagger$ Electronic supplementary information (ESI) available. See DOI: 10.1039/ c4ce01696c 


\section{Experimental procedure}

The cabbage-like $\beta-\mathrm{Co}(\mathrm{OH})_{2}$ nanostructures were synthesized by the one-step ED process using a simple two-electrode system. Herein, the platinum (Pt) mesh and conductive textile were used as the anode and the cathode, respectively. For preparing the growth solution, all of the chemicals were of analytical grade and used as purchased without further purification. To employ the conductive textile as a substrate, the commercially available conductive textile composed of copper (Cu)-coated polyethylene terephthalate (PET) fibers was used. Before preparing the growth solution for the ED process, the conductive textile substrates were cut into a size of $2 \mathrm{~cm} \times 2 \mathrm{~cm}$ and cleaned with acetone and de-ionized (DI) water in an ultrasonic bath for $10 \mathrm{~min}$. After cleaning the conductive textile, it was dried under a flow of nitrogen gas. Meanwhile, the growth solution was prepared by dissolving $10 \mathrm{mM}$ cobalt(II) nitrate hexahydrate $\left(\mathrm{Co}\left(\mathrm{NO}_{3}\right)_{2} \cdot 6 \mathrm{H}_{2} \mathrm{O}\right.$, Sigma-Aldrich Chemicals) and $10 \mathrm{mM}$ hexamethylenetetramine (HMTA, $\mathrm{C}_{6} \mathrm{H}_{12} \mathrm{~N}_{4}$, Sigma-Aldrich Chemicals) into $900 \mathrm{ml}$ of DI water at $\sim 72-75^{\circ} \mathrm{C}$, which creates a pink-colored solution during the reaction. Then, the conductive textile was carefully immersed into the growth solution and each electrode was connected to a direct current power supply. During the ED process, the growth solution was slowly stirred by a magnetic bar. By applying a constant external applied voltage of $-0.75 \mathrm{~V}$ between two electrodes, the $\beta-\mathrm{Co}(\mathrm{OH})_{2}$ was grown on the conductive textile at different growth times from $30 \mathrm{~min}$ to $8 \mathrm{~h}$. After the ED process, the sample was carefully pulled out and cleaned by flowing DI water.

\subsection{Characterization}

The surface morphology and structural properties of the as-prepared samples were characterized by using a field-emission scanning electron microscope (FE-SEM, LEO SUPRA 55, Carl Zeiss), a transmission electron microscope (TEM, JEM 200CX, JEOL), and a $2 \theta$ scan X-ray diffractometer (XRD, Mac Science, M18XHFSRA). The samples were further characterized by X-ray photoelectron spectroscopy (XPS, THERMO MULTILAB 2000 SYSTEM) and Fourier transform infrared spectroscopy (FT-IR, JASCO FT-IR 470 PLUS SPECTROMETER) measurements.

\subsection{Electrochemical measurements}

The electrochemical measurements were performed using a three-electrode testing system composed of $\mathrm{Ag} / \mathrm{AgCl}$ as the reference electrode, Pt wire as the counter electrode, and $\beta-\mathrm{Co}(\mathrm{OH})_{2}$ nanostructures on the conductive textile as the working electrode. Herein, $1 \mathrm{M} \mathrm{KOH}$ aqueous solution was used as an electrolyte. Cyclic voltammetry (CV) curve characteristics were measured at $30 \mathrm{mV} \mathrm{s}^{-1}$ under voltages between -0.1 and $0.5 \mathrm{~V}$ and galvanic charge-discharge (GCD) test was performed in the voltage range of -0.1 to $0.5 \mathrm{~V}$ at a constant current density of $1 \mathrm{~A} \mathrm{~g}^{-1}$. All of the electrochemical measurements were carried out by using an IVIUMSTAT electrochemical analyzer.

\section{Results and discussion}

Fig. 1 shows the FE-SEM images of the fabricated cabbage-like $\beta-\mathrm{Co}(\mathrm{OH})_{2}$ nanostructures on the conductive textile substrate. Here, the ED process was carried out with an external voltage of $-0.75 \mathrm{~V}$ for $4 \mathrm{~h}$. From the perspective view of the FE-SEM image in Fig. 1(a), the surfaces of the textile fibers were well decorated with hierarchical $\beta-\mathrm{Co}(\mathrm{OH})_{2}$ nanostructures. As shown in the photographic images in the inset of Fig. 1(a), it can be observed that the conductive textile was uniformly covered by $\beta-\mathrm{Co}(\mathrm{OH})_{2}$ without any voids or gaps, exhibiting a pinkish-brown color, in comparison with the bare conductive textile substrate. In the magnified view of the FE-SEM image (Fig. 1(b)), it is clearly seen that the $\beta-\mathrm{Co}(\mathrm{OH})_{2}$ nanostructures were well adhered to the textile fiber and their sizes were estimated to be $\sim 4-4.5 \mu \mathrm{m}$. These $\beta-\mathrm{Co}(\mathrm{OH})_{2}$ nanostructures exhibited a cabbage-like morphology and were assembled by plenty of interconnected and curved nanoplates in Fig. 1(c). During the ED process, initially, the precipitated $\beta-\mathrm{Co}(\mathrm{OH})_{2}$ nanoparticles were strongly immobilized, thus providing the nucleation sites for the formation of nano-crystalline sheets onto the overall surface of the working electrode. However, under the continuous supply of electrons, these primary nanosheets contributed to further growth of other nanoplates, which leads to the multilayered nanoplate assembly. In fact, the increased nucleation sites on previously formed nanoplates guided the growth of multilayered nanoplates. ${ }^{20}$ Thus, the spherical contours of cabbage-like morphology were formed by the tangled layers of nanoplates. From the high-magnification view of the FE-SEM image in Fig. $1(\mathrm{~d})$, the cabbage-like $\beta-\mathrm{Co}(\mathrm{OH})_{2}$ nanostructures were composed of multiple nanoplates with thicknesses of approximately 45-55 $\mathrm{nm}$. To illustrate the structure of grown $\beta-\mathrm{Co}(\mathrm{OH})_{2}$ nanostructures, the schematic diagram is shown in Fig. 1(e).

To understand the formation mechanism of the selfassembled cabbage-like $\beta-\mathrm{Co}(\mathrm{OH})_{2}$ nanostructures on the conductive textile substrate, the growth time was varied under the same external applied voltage of $-0.75 \mathrm{~V}$. In the ED process, generally, the formation of $\beta-\mathrm{Co}(\mathrm{OH})_{2}$ is based on the generation of hydroxyl ions at the surface of the working electrode. When the substrate was immersed in the growth solution, the nitrate $\left(\mathrm{NO}_{3}^{-}\right)$ions were electrochemically reduced with water on the working substrate, leading to the formation of hydroxyl $\left(\mathrm{OH}^{-}\right)$ions and nitrite $\left(\mathrm{NO}_{2}^{-}\right)$ions by the support of electrons. Subsequently, the cobalt $\left(\mathrm{Co}^{2+}\right)$ ions in the vicinity of the working electrode react with the $\mathrm{OH}^{-}$ions, resulting in the formation of precipitated cobalt hydroxide on the working substrate and providing the subsequent nucleation sites. ${ }^{21}$ As shown in Fig. 2(a), the surface of the conductive textile fibers was uniformly covered with thin $\beta-\mathrm{Co}(\mathrm{OH})_{2}$ nanosheets at the growth time of $30 \mathrm{~min}$. As-grown nanosheets have thicknesses of $\sim 15-20 \mathrm{~nm}$ (see the inset of Fig. 2(a)). When the growth time was increased to $1 \mathrm{~h}$, some nanoplates were formed due to the increased crystal nuclei on the nanosheets. After $1.5 \mathrm{~h}$, the nanoplates were more stacked and shaped into the multilayered nanoplates with increased diameters as 

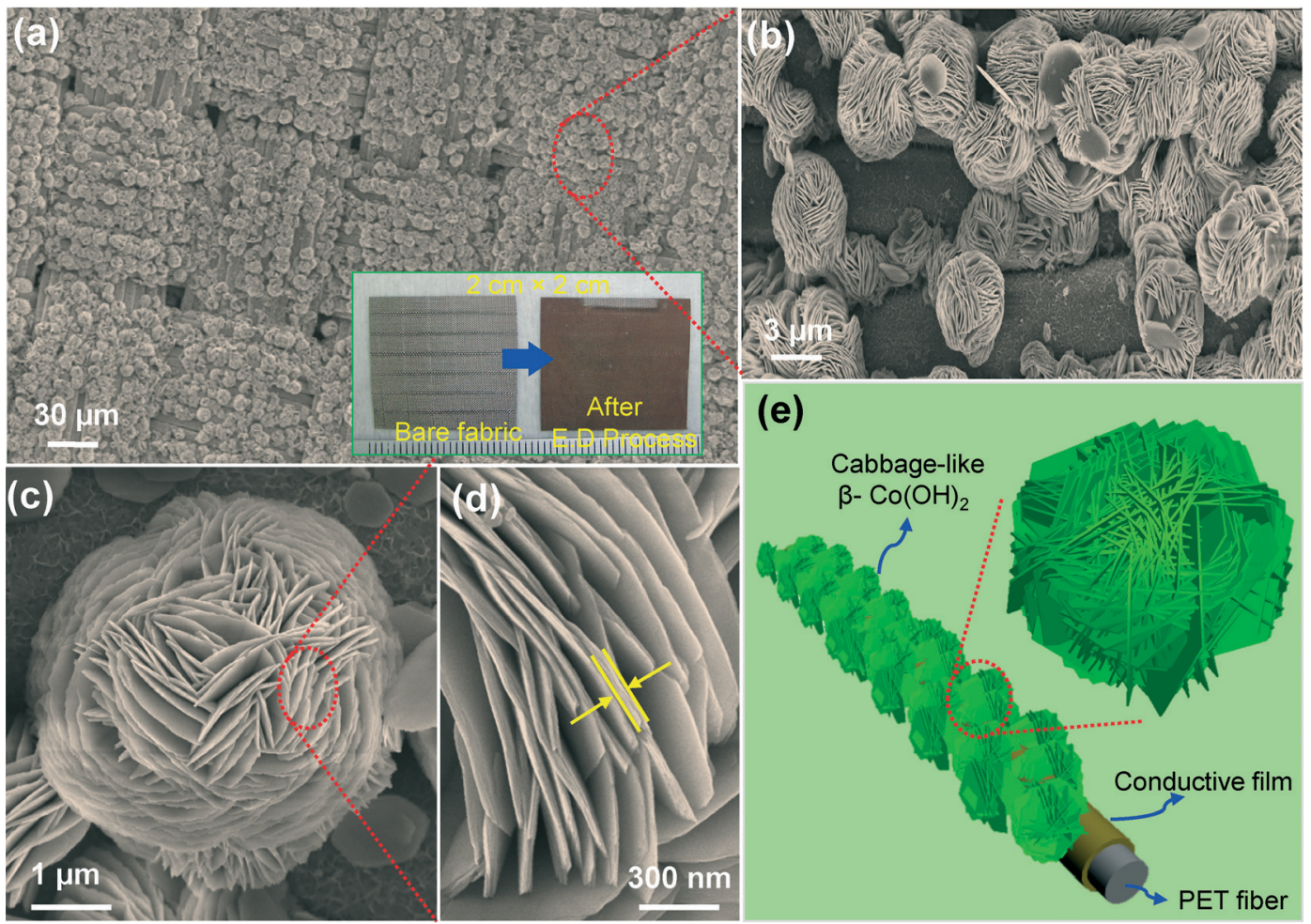

Fig. 1 FE-SEM images of the cabbage-like $\beta-\mathrm{Co}(\mathrm{OH})_{2}$ nanostructures on the conductive textile substrate synthesized at an external applied voltage of $-0.75 \mathrm{~V}$ for $4 \mathrm{~h}$ : (a) perspective view and (b-d) high-magnification views. (e) 3D schematic diagram of the corresponding structures. The inset of (a) shows the photographic images of the conductive textile fabric before and after ED.

shown in Fig. 2(c). In general, the nucleation and growth processes are prolonged, ensuring a well-defined matrix with strong coagulation of nanoplates together. As a result, the multilayered nanoplates could be assembled from the nanoplate morphology. These multilayered nanoplates were gradually molded and they were partially formed as cabbage-like $\beta-\mathrm{Co}(\mathrm{OH})_{2}$ nanostructures at the growth time of $2 \mathrm{~h}$ (see Fig. 2(d)). When the growth time reached $4 \mathrm{~h}$, the cabbage-like morphology of self-assembled nanoplates was completely formed on the textile surface by the oriented attachment, as can be seen in Fig. 2(e). The nanoplates in the cabbage-like $\beta-\mathrm{Co}(\mathrm{OH})_{2}$ nanostructures were compactly and closely gathered around each other with further increase in the reaction time to $8 \mathrm{~h}$ as shown in Fig. 2(f). In fact, during the self-assembly process, the exterior crystallites on the multilayered nanoplates served as starting points to attract the smaller metastable crystallites in the growth solution. Through this process, the multilayered nanoplates were grown step by step into cabbage-like structures via the nanoplate morphology. ${ }^{22}$ The photographic images of the $\beta-\mathrm{Co}(\mathrm{OH})_{2}$ nanostructures on conductive textile substrates at different growth times are shown in Fig. S1 of the ESI.† This formation mechanism can be explained by the fact that the ionic species strongly accumulated on the specific crystal surface of the already formed nanosheet under the electric field in the growth solution. Therefore, $\beta-\mathrm{Co}(\mathrm{OH})_{2}$ nanoplates were grown on the conductive fiber surface with an average diameter of a few hundred nanometers. However, under the continuously induced electric field in the growth solution, the nanosheets and nanoplates further offered the subsequent nucleation sites for the oriented branch growth of multilayered nanoplates. Finally, these multilayered nanoplates were selfassembled by each other, forming cabbage-like $\beta-\mathrm{Co}(\mathrm{OH})_{2}$ nanostructures on the surface of the conductive textile substrate, which is schematically explained in Fig. $2(\mathrm{~g})$.

Fig. 3 shows the (a) $2 \theta$ scan XRD pattern, (b) TEM images, and (c) high-resolution TEM (HRTEM) image of the cabbagelike $\beta-\mathrm{Co}(\mathrm{OH})_{2}$ on the conductive textile substrate. The selective area electron diffraction (SAED) pattern of the corresponding sample is shown in the inset of (c). The as-grown sample was confirmed by the $2 \theta$ scan XRD analysis. The XRD pattern of the fabricated sample was indexed to JCPDS card no. 30-0443 and 85-1326. These correspond to $\mathrm{Cu}$ crystal structures and brucitelike $\beta-\mathrm{Co}(\mathrm{OH})_{2}$. The main XRD peaks were observed at 19.08, 32.5 , and $37.9^{\circ}$ related to the (001), (100), and (101) planes of $\beta-\mathrm{Co}(\mathrm{OH})_{2}$ on the conductive textile, respectively. Also, the substrate peaks of $\mathrm{Cu}$ were observed at 43.3 and $50.4^{\circ}$ corresponding to the crystal planes of (111) and (200) with PET fiber peaks, respectively. Without any impurities, the XRD pattern confirmed that the well-crystallized cabbage-like $\beta-\mathrm{Co}(\mathrm{OH})_{2}$ nanostructures were decorated on the conductive textile by the ED process. In order to obtain the TEM images, the sample was scrapped into small pieces and mixed with ethanol solution followed by ultrasonication for $20 \mathrm{~min}$ to separate cabbage-like $\beta-\mathrm{Co}(\mathrm{OH})_{2}$ nanostructures from the conductive textile substrate. Then, the ethanol solution containing cabbage-like $\beta-\mathrm{Co}(\mathrm{OH})_{2}$ nanostructures was dropped onto the copper grid and then 

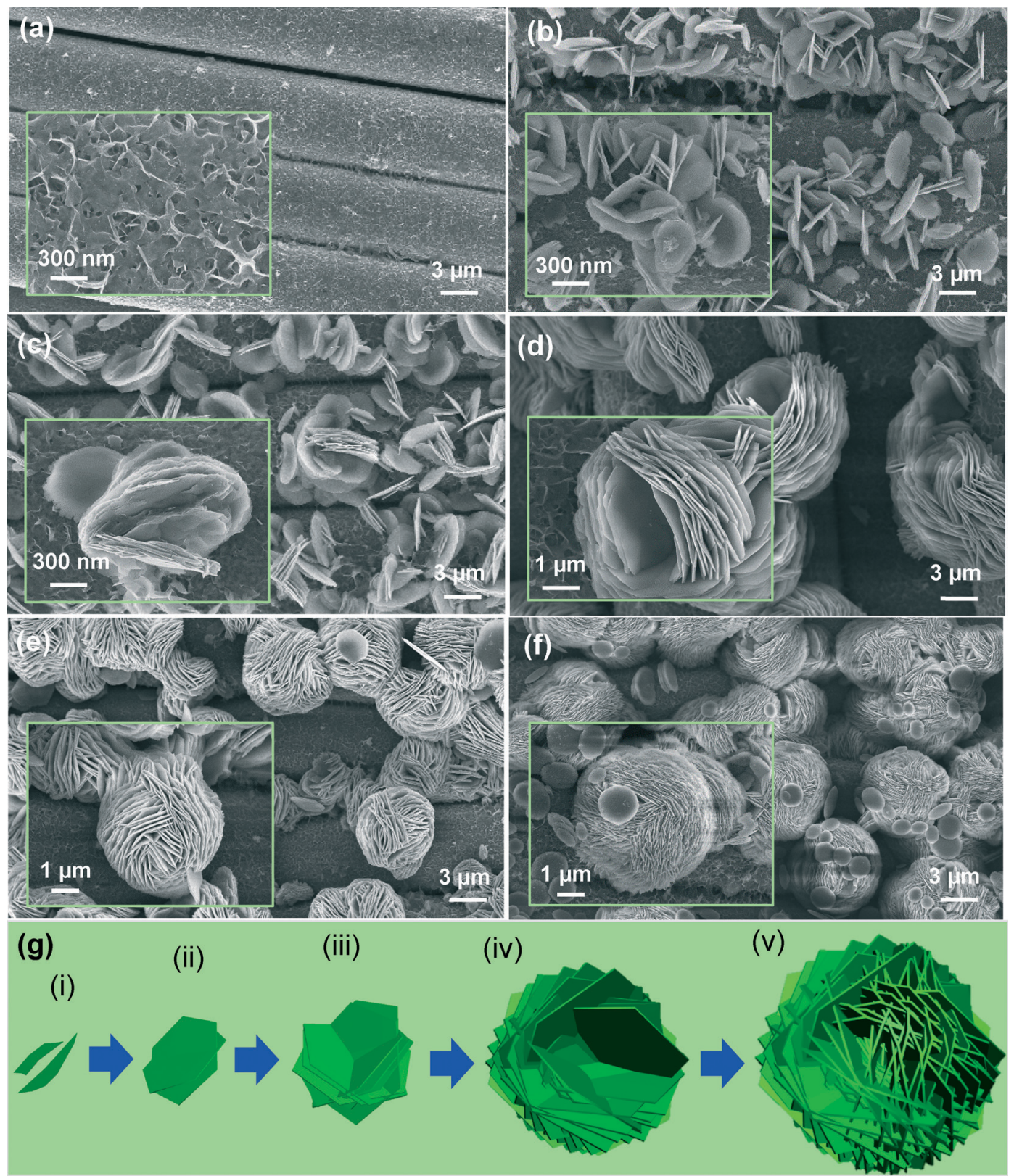

Fig. 2 FE-SEM images of the cabbage-like $\beta-\mathrm{Co}(\mathrm{OH})_{2}$ nanostructures on the conductive textile at different growth times of (a) 30 min, (b) $1 \mathrm{~h}$, (c) $1.5 \mathrm{~h} \mathrm{(d)} 2 \mathrm{~h}$ (e) $4 \mathrm{~h}$, and (f) $8 \mathrm{~h}$ under the constant external applied voltage of $-0.75 \mathrm{~V}$. (g) Schematic illustration of the structural formation of the cabbage-like $\beta-\mathrm{Co}(\mathrm{OH})_{2}$ nanostructures.

dried in air before transferring it to the microscope chamber. From the low-magnification TEM image in Fig. 3(b), the edge part of the cabbage-like $\beta-\mathrm{Co}(\mathrm{OH})_{2}$ nanostructure could be observed and it confirmed that the hierarchical cabbage-like structure is composed of multilayered nanoplates. The stacked nanoplates are clearly seen in the inset of Fig. 3(b). The average size of nanoplates was estimated to be approximately $350-500 \mathrm{~nm}$. In Fig. 3(c), the lattice spacing between the two planes was $0.237 \mathrm{~nm}$, which is in good agreement with the (101) crystal plane of $\beta-\mathrm{Co}(\mathrm{OH})_{2}$. As can be seen in the inset of Fig. 3(c), the dotted spots in the SAED pattern clearly indicate that the prepared $\beta-\mathrm{Co}(\mathrm{OH})_{2}$ sample was assembled by single crystals along the preferential orientation.
Fig. 4 shows the FT-IR spectrum and XPS analysis of the cabbage-like $\beta-\mathrm{Co}(\mathrm{OH})_{2}$ nanostructures. As shown in the FT-IR spectra of Fig. 4(a), the characteristic sharp band observed at $3631 \mathrm{~cm}^{-1}$ can be assigned to the $\mathrm{O}-\mathrm{H}$ stretching vibration of the free $\mathrm{Co}-\mathrm{OH}$ groups within the brucite-like layers. The strong peak of $\mathrm{O}-\mathrm{H}$ stretching vibration in the spectrum clearly indicates that the hydroxyl groups in the layered structure were strongly coupled with hydrogen bonding via a hydration process intercalating interlayer water molecules. The peak observed at $1633 \mathrm{~cm}^{-1}$ is caused by the bending mode of water molecule deformation vibration. The bending vibration mode of $\mathrm{Co}-\mathrm{OH}$ peak was also observed at $489 \mathrm{~cm}^{-1}$ in the $\beta$-phase. In the XPS analysis of Fig. $4(\mathrm{~b})$, 

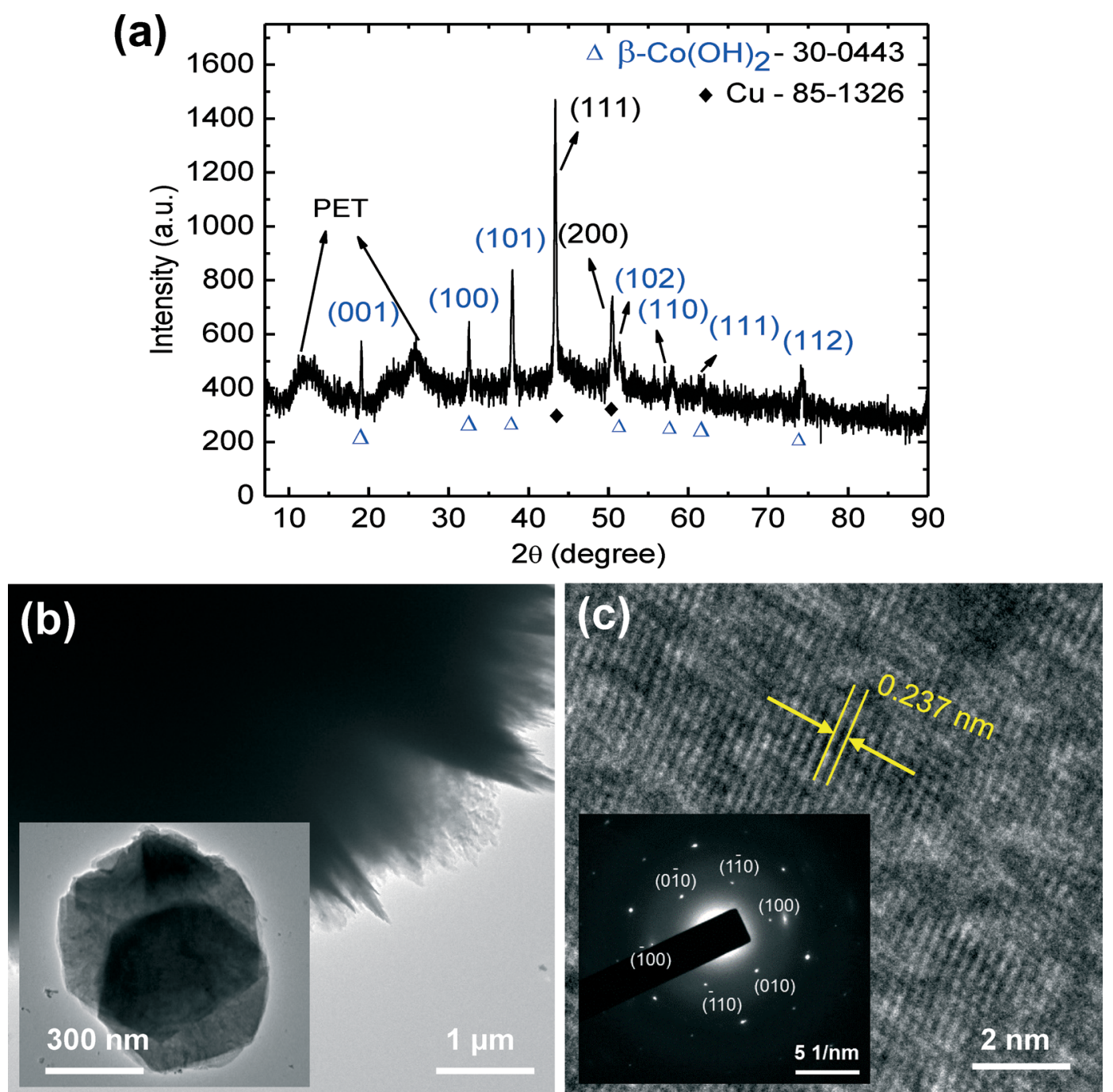

Fig. 3 (a) $2 \theta$ scan XRD pattern, (b) TEM images, and (c) HRTEM image of the cabbage-like $\beta-\mathrm{Co}(\mathrm{OH})_{2}$ nanostructures on the conductive textile substrate. The inset of (c) shows the SAED pattern of the corresponding sample.

the chemical composition in the cabbage-like $\beta-\mathrm{Co}(\mathrm{OH})_{2}$ was examined with the peaks of Co 2 p, O 1s, and $\mathrm{C} 1 \mathrm{~s}$ regions, which clearly indicate the presence of cobalt, oxygen, and carbon in the fabricated sample. As shown in the Co $2 \mathrm{p}$ spectrum (Fig. 4(c)), the main peaks were observed at 780.4 and $797.17 \mathrm{eV}$ corresponding to the Co $2 \mathrm{p}_{3 / 2}$ and Co $2 \mathrm{p}_{1 / 2}$, respectively. In the O 1s spectra (Fig. 4(d)), the peak observed at $531.09 \mathrm{eV}$ can be attributed to the shoulder peak of oxygen atoms in $\beta-\mathrm{Co}(\mathrm{OH})_{2}$. The $\mathrm{C}$ 1s spectrum in the inset of Fig. 4(d) shows the characteristic peak at $284.38 \mathrm{eV}$, and small peaks at 285.57 and $286.27 \mathrm{eV}$ correspond to the hydrocarbon in the substrate, $\mathrm{C}=\mathrm{O}$, and $\mathrm{C}-\mathrm{OH}$ groups. These results confirm that the cabbage-like $\beta$ - $\mathrm{Co}(\mathrm{OH})_{2}$ nanostructures were fabricated on the surface of the conductive textile fabric.

To investigate the feasibility for supercapacitors, we measured the electrochemical properties by CV and GCD measurements using a three-electrode system at room temperature in $1 \mathrm{M} \mathrm{KOH}$ aqueous solution. The fabricated $\beta-\mathrm{Co}(\mathrm{OH})_{2}$ nanostructures on the conductive textile (area of $1.5 \mathrm{~cm}^{2}$ ) were directly used as the working electrode, and the Pt wire and the $\mathrm{Ag} / \mathrm{AgCl}$ were used as counter and reference electrodes, respectively. Fig. 5(a) shows the measured CV curves of the as-prepared $\beta-\mathrm{Co}(\mathrm{OH})_{2}$ nanostructures on the conductive textile at a scan rate of $30 \mathrm{mV} \mathrm{s}^{-1}$ within the potential window of approximately -0.1 to $0.5 \mathrm{~V}$ for both nanoplates and cabbage-like $\beta-\mathrm{Co}(\mathrm{OH})_{2}$ nanostructures on the conductive textiles. For two CV curves, it commonly exhibited a normal rectangular shape. Furthermore, these curves were distinguished from electric double-layer capacitance with two pairs of redox peaks. The anodic and cathodic peaks were caused by the quasireversible reactions occurring at the electrode/electrolyte interface during the potential sweep as follows: ${ }^{23,24}$

$$
\begin{aligned}
& \mathrm{Co}(\mathrm{OH})_{2}+\mathrm{OH}^{-} \leftrightarrow \mathrm{CoOOH}+\mathrm{H}_{2} \mathrm{O}+\mathrm{e}^{-} \text {and } \\
& \mathrm{CoOOH}+\mathrm{OH}^{-} \leftrightarrow \mathrm{CoO}_{2}+\mathrm{H}_{2} \mathrm{O}+\mathrm{e}^{-} .
\end{aligned}
$$

Compared to the CV curve of the cabbage-like $\beta-\mathrm{Co}(\mathrm{OH})_{2}$ nanostructures, the $\mathrm{CV}$ curve of the bare conductive textile 
(a)
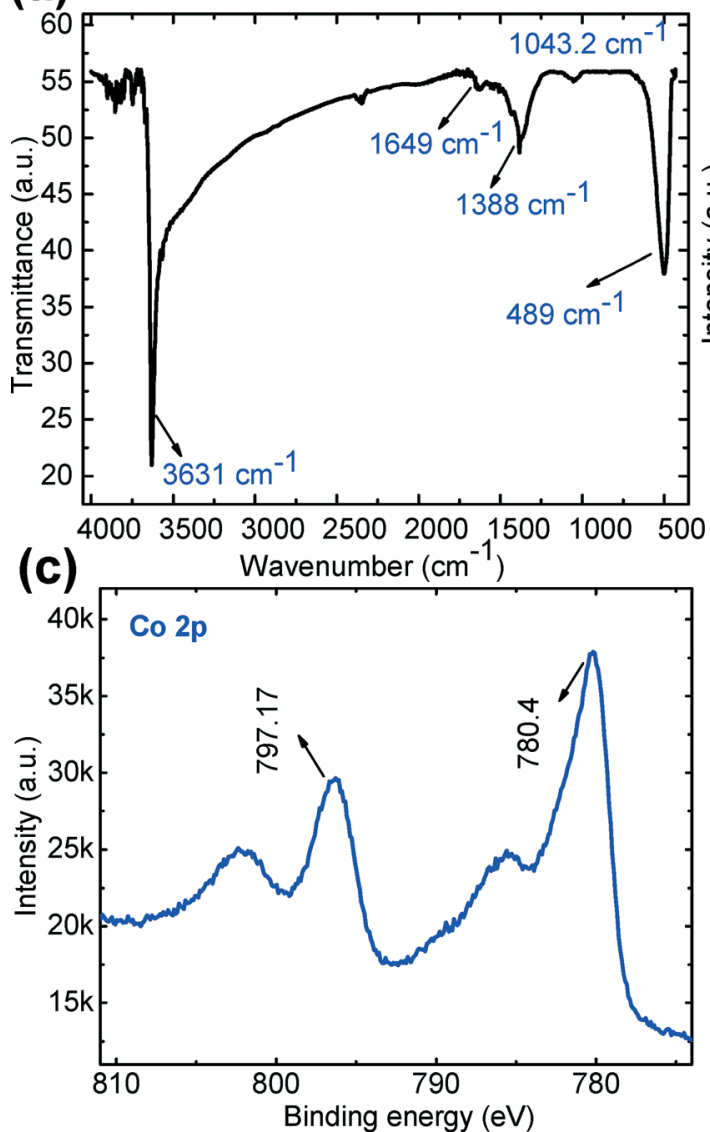

(b)
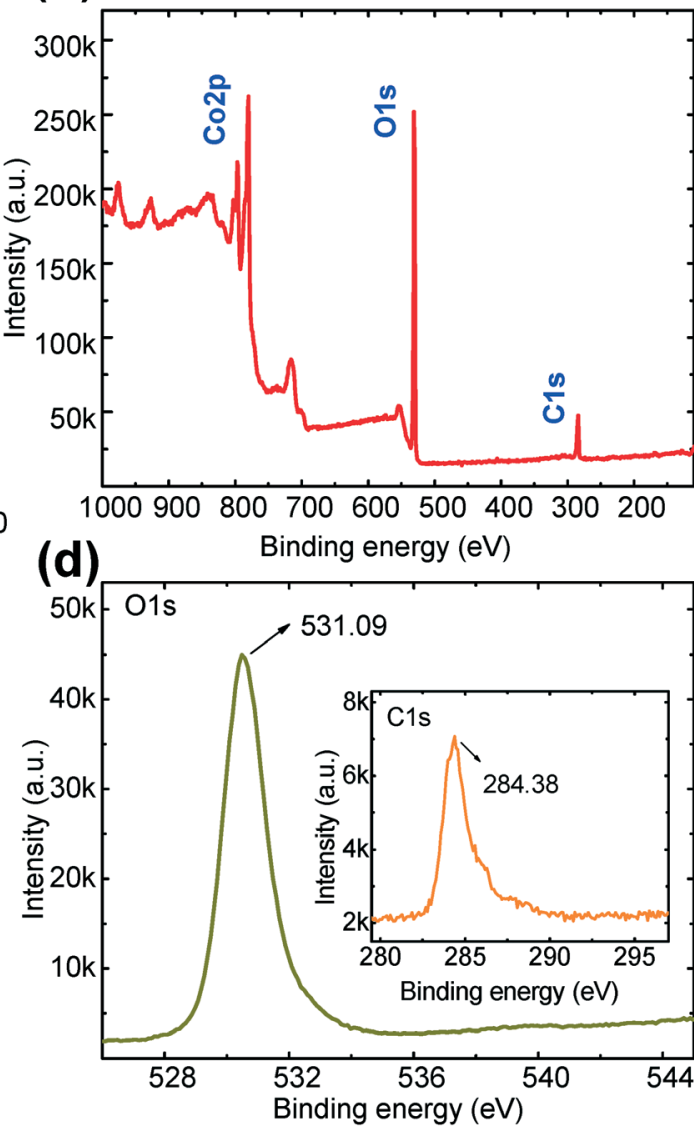

Fig. 4 (a) FT-IR spectrum and (b) XPS spectrum of the cabbage-like $\beta-\mathrm{Co}(\mathrm{OH})_{2}$ nanostructures on the conductive textile substrate. (c) Co $2 p$ and (d) $\mathrm{O} 1 \mathrm{~s}, \mathrm{C} 1 \mathrm{~s}$ (inset) spectra.

(a)

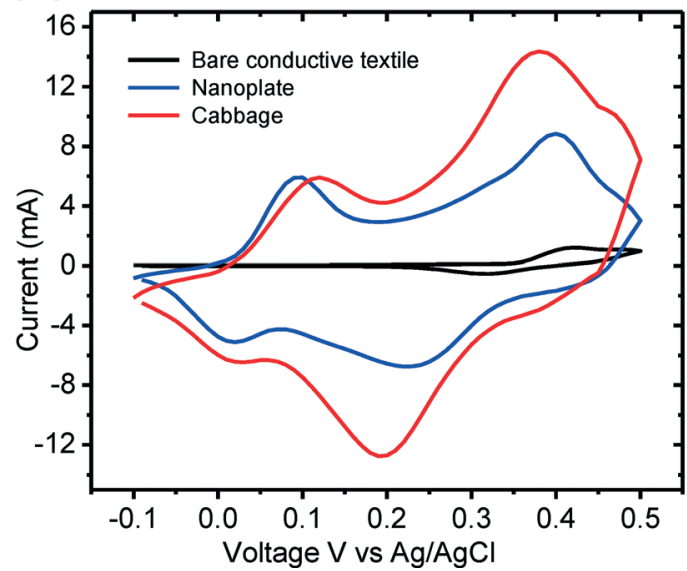

(b)

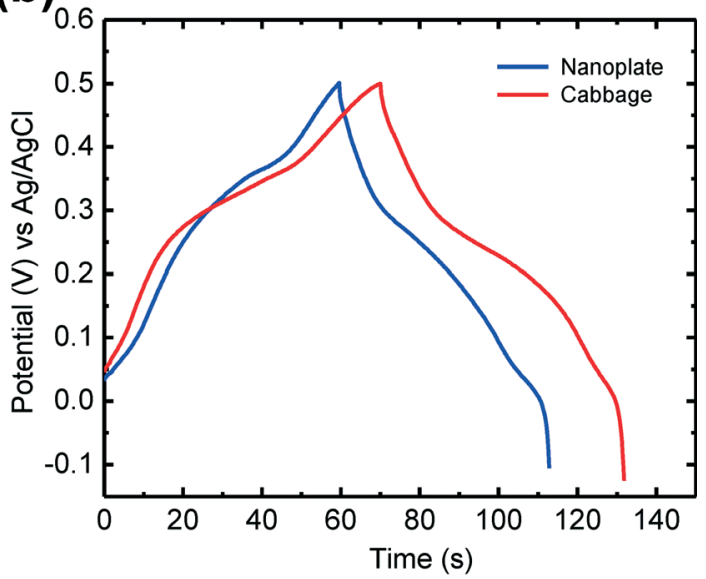

Fig. 5 (a) Cyclic voltammetry curves and (b) galvanic charge-discharge plots of the nanoplates and cabbage-like $\beta-\mathrm{Co}(\mathrm{OH})_{2}$ nanostructures on the conductive textile substrate.

(black color) was relatively small, indicating that the conductive textile contributes little to the total energy storage capacitance of the electrode. Also, it could be clearly observed that the area integrated with the cabbage-like $\beta-\mathrm{Co}(\mathrm{OH})_{2}$ nanostructures in the CV curve is larger than that of the $\beta-\mathrm{Co}(\mathrm{OH})_{2}$ nanoplates. This is mainly caused by the fact that the $3 \mathrm{D}$ cabbage-like nanostructures provide increased channels for the charge transportation and facilitate deep penetration of electrolyte 
ions into the active sites on the electrode surface. Therefore, the surface area of the cabbage-like $\beta-\mathrm{Co}(\mathrm{OH})_{2}$ nanostructures on the conductive textile substrate for electrochemical reaction was increased, and thus superior energy storage properties than those of the $\beta-\mathrm{Co}(\mathrm{OH})_{2}$ nanoplates were obtained. ${ }^{25}$ To evaluate the specific capacitance of the $\beta-\mathrm{Co}(\mathrm{OH})_{2}$ nanostructures on the conductive textile substrate, GCD measurements were carried out at a constant current density of $1 \mathrm{~A} \mathrm{~g}^{-1}$ in the three electrode system. The specific capacitance of the $\beta-\mathrm{Co}(\mathrm{OH})_{2}$ nanostructures can be calculated according to the following equation: ${ }^{24}$

$$
C_{\mathrm{m}}=I \Delta t /(m \Delta V)
$$

where $C_{\mathrm{m}}\left(\mathrm{F} \mathrm{g}^{-1}\right)$ is the specific capacitance, $I(\mathrm{~mA})$ is the applied charge-discharge current, $\Delta t(\mathrm{~s})$ is the discharge time, $m(\mathrm{mg})$ is the mass of the $\beta-\mathrm{Co}(\mathrm{OH})_{2}$ nanostructures deposited on the conductive textile substrate, and $\Delta V(\mathrm{~V})$ is the potential drop during the discharge time. Fig. 5(b) shows the GCD curves of the nanoplate and cabbage-like nanostructures deposited on the conductive textile substrate. On comparing both the curves, the cabbage-like $\beta-\mathrm{Co}(\mathrm{OH})_{2}$ nanostructures grown on the conductive textile electrode exhibited the maximum charging and discharging times. The calculated specific capacitance values for both the nanoplate and cabbage-like $\beta$-Co $(\mathrm{OH})_{2}$ nanostructures were 96.8 and $108.7 \mathrm{~F} \mathrm{~g}^{-1}$, respectively, which are higher than the results reported before. ${ }^{19}$ The cabbage-like $\beta-\mathrm{Co}(\mathrm{OH})_{2}$ nanostructure exhibited higher specific capacitance values than the $\beta-\mathrm{Co}(\mathrm{OH})_{2}$ nanoplates. This could be explained by the fact that the cabbage-like $\beta-\mathrm{Co}(\mathrm{OH})_{2}$ nanostructures were assembled by the intertwined multi-layered nanoplates, allowing easy accessibility of hydroxyl ions among them and shortening diffusion paths for electrons and ions. These cabbage-like $\beta-\mathrm{Co}(\mathrm{OH})_{2}$ nanostructures also provide a relatively large electroactive surface area for highly feasible redox reactions. These features in the cabbage-like $\beta-\mathrm{Co}(\mathrm{OH})_{2}$ nanostructures were helpful in obtaining high specific capacitance values compared to the $\beta-\mathrm{Co}(\mathrm{OH})_{2}$ nanoplates on the conductive textile substrate. ${ }^{26}$ This facile fabrication method could be extended to the growth of various $\mathrm{NiCo}_{2} \mathrm{O}_{4} / \mathrm{Ni}-\mathrm{Co}$ layered double hydroxide like nanomaterials on wearable conductive textile substrates for better electrochemical properties. ${ }^{27}$

\section{Conclusion}

The ED process was carried out for the fabrication of $3 \mathrm{D}$ cabbage-like $\beta$-Co(OH $)_{2}$ hierarchical structures on the conductive textile substrate. By applying an external voltage of $-0.75 \mathrm{~V}$ for $4 \mathrm{~h}$, the cabbage-like nanostructures were densely assembled and firmly decorated onto the conductive textiles. Cabbage-like $\beta$-Co(OH $)_{2}$ nanostructures were formed by the self-assembly of multilayered nanoplates. By varying the growth time under the external applied voltage of $-0.75 \mathrm{~V}$, the growth mechanism of the cabbage-like $\beta-\mathrm{Co}(\mathrm{OH})_{2}$ nanostructures was investigated. Under the continuous supply of electrons in the growth solution, initially formed nanosheet and nanoplate structures provided the nucleation sites for the growth of intertwined and multilayered nanoplates. These were further oriented by the self-assembly process and formed to the cabbagelike $\beta-\mathrm{Co}(\mathrm{OH})_{2}$ nanostructures. The FE-SEM, TEM, XRD, FT-IR, and XPS analyses confirmed that the cabbage-like $\beta-\mathrm{Co}(\mathrm{OH})_{2}$ nanostructures were well decorated on the conductive textile substrate with good crystallinity. Additionally, electrochemical properties suggest that the cabbage-like $\beta-\mathrm{Co}(\mathrm{OH})_{2}$ nanostructures revealed better energy storage performance. This facile process for cabbage-like $\beta$-Co(OH $)_{2}$ nanostructures on conductive textiles can be expected to be a promising fabrication method for flexible, wearable energy storage and electronic device applications.

\section{Acknowledgements}

This research was supported by the Basic Science Research Program through the National Research Foundation of Korea (NRF) funded by the Ministry of Science, ICT and Future Planning (no. 2013-068407).

\section{References}

1 T. Ameri, N. Li and C. J. Brabec, Energy Environ. Sci., 2013, 6, 2390-2413.

2 Y.-G. Guo, J.-S. Hu and L.-J. Wan, Adv. Mater., 2008, 20, 2878-2887.

3 L. Yu, G. Zhang, C. Yuan and X. W. Lou, Chem. Commun., 2013, 49, 137-139.

4 B. Liu, T. Luo, G. Mu, X. Wang, D. Chen and G. Shen, ACS Nano, 2013, 7, 8051-8058.

5 B. Liu, Z. Wang, Y. Dong, Y. Zhu, Y. Gong, S. Ran, Z. Liu, J. Xu, Z. Xie, D. Chen and G. Shen, J. Mater. Chem., 2012, 22, 9379-9384.

6 L. Yuan, X.-H. Lu, X. Xiao, T. Zhai, J. Dai, F. Zhang, B. Hu, X. Wang, L. Gong, J. Chen, C. Hu, Y. Tong, J. Zhou and Z. L. Wang, ACS Nano, 2011, 6, 656-661.

7 L. Hu, M. Pasta, F. L. Mantia, L. Cui, S. Jeong, H. D. Deshazer, J. W. Choi, S. M. Han and Y. Cui, Nano Lett., 2010, 10, 708-714.

8 L. Wu, R. Li, J. Guo, C. Zhou, W. Zhang, C. Wang, Y. Huang, Y. Li and J. Liu, AIP Advances, 2013, 3, 082129.

9 H. B. Li, M. H. Yu, X. H. Lu, P. Liu, Y. Liang, J. Xiao, Y. X. Tong and G. W. Yang, ACS Appl. Mater. Interfaces, 2014, 6, 745-749.

10 H. Chen, L. Hu, M. Chen, Y. Yan and L. Wu, Adv. Funct. Mater., 2014, 24, 934-942.

11 Y. Wang, H. Wang and X. Wang, Electrochim. Acta, 2013, 92, 298-303.

12 Y. Zhang, B. Cui, O. Derr, Z. Yao, Z. Qin, X. Deng, J. Li and H. Lin, Nanoscale, 2014, 6, 3376-3383.

13 Y. Ge, K. Kan, Y. Yang, L. Zhou, L. Jing, P. Shen, L. Li and K. Shi, J. Mater. Chem. A, 2014, 2, 4961-4969.

14 Z. Liu, R. Ma, M. Osada, K. Takada and T. Sasaki, J. Am. Chem. Soc., 2005, 127, 13869-13874.

15 S. Faraji and F. N. Ani, J. Power Sources, 2014, 263, 338-360. 
16 Y. Xiao, S. Liu, F. Li, A. Zhang, J. Zhao, S. Fang and D. Jia, Adv. Funct. Mater., 2012, 22, 4052-4059.

17 R. Wang, X. Yan, J. Lang, Z. Zheng and P. Zhang, J. Mater. Chem. A, 2014, 2, 12724-12732.

18 D. Ghosh, S. Giri and C. K. Das, ACS Sustainable Chem. Eng., 2013, 1, 1135-1142.

19 C. Li, X. Zhang, P. Yu, H. Zhang, X. Sun and Y. Ma, CrystEngComm, 2014, 16, 7478-7485.

20 Y. H. Ko, S. Kim, W. Park and J. S. Yu, Phys. Status Solidi $R R L, 2012,6,355-357$.

21 J. R. S. Brownson and C. Lévy-Clément, Phys. Status Solidi B, 2008, 245, 1785-1791.
22 W. Yang, Z. Gao, J. Wang, J. Ma, M. Zhang and L. Liu, ACS Appl. Mater. Interfaces, 2013, 5, 5443-5454.

23 J. Zhang, L.-B. Kong, J.-J. Cai, Y.-C. Luo and L. Kang, J. Solid State Electrochem., 2010, 14, 2065-2075.

24 X. Ji, P. M. Hallam, S. M. Houssein, R. Kadara, L. Lang and C. E. Banks, RSC Adv., 2012, 2, 1508-1515.

25 S. Xiong, C. Yuan, X. Zhang, B. Xi and Y. Qian, Chem. - Eur. J., 2009, 15, 5320-5326.

26 X. Chen, J. P. Cheng, Q. L. Shou, F. Liu and X. B. Zhang, CrystEngComm, 2012, 14, 1271-1276.

27 L. Hu, L. Wu, M. Liao and X. Fang, Adv. Mater., 2011, 23, 1988-1992. 